\title{
A novel approach using a fouling index to evaluate NOM fouling behavior in a low pressure ultrafiltration process
}

\author{
Ping Xiao, Weijun Zhang, Feng Xiao, Zhe Bi and Dongsheng Wang
}

\begin{abstract}
A fouling index (FI) was introduced as a novel approach to investigate natural organic matter (NOM) fouling behavior in a low pressure membrane ultrafiltration process. Humic acid (HA), bovine serum albumin (BSA) and sodium alginate (SA), were used in the experiments. According to FI values, fouling was caused by NOM in two steps: a fast fouling process followed by a slow one. FI of the fast stage $\left(\mathrm{FI}_{\mathrm{F}}\right)$ was much greater than that of the slow one $\left(\mathrm{FI}_{\mathrm{S}}\right)$, showing the initial interaction would play a significant role in the fouling process over a short time. The results of mass balance suggested that a small fraction of DOC was responsible for membrane fouling caused by adsorption. Furthermore, both hydrophobic interaction and electrostatic interaction between NOM and the membrane determined the fouling behavior. Only a portion of foulants was removed after hydraulic washing. The sequence of NOM causing irreversible fouling was BSA $>\mathrm{HA}>\mathrm{SA}$, and the sequence of irreversible fouling after alkaline cleaning was SA $>$ BSA $>$ HA. The variations of FI values were consistent with the results of mass balances and flux recovery, which confirmed the FI was a simple and effective tool to describe the membrane fouling process.
\end{abstract}

Key words | bovine serum albumin (BSA), fouling index, humic acid (HA), low pressure ultrafiltration membrane, natural organic matter (NOM), sodium alginate (SA)

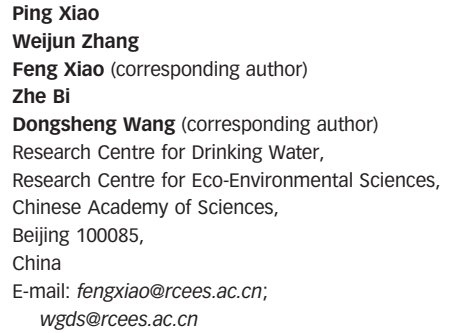

\section{$\overline{\text { INTRODUCTION }}$}

Low pressure membrane (LPM) filtration is one of the most important technologies in drinking water and wastewater treatment. However, membrane fouling is still a major obstacle to practical application. Previous research has reported that natural organic matter (NOM) such as humic substances (HS), protein and polysaccharides, led to serious organic fouling (Fan et al. 200I; Howe \& Clark 2002; Yamamura et al. 2007; Peter-Varbanet et al. 20II). The interactions between foulant-foulant and foulantmembrane influence the whole fouling behavior. The membrane fouling mechanisms included adsorption, pore blocking, and the accumulation of cake layer and gel layer. Therefore, it is difficult to estimate and evaluate the membrane fouling process clearly.

Huang et al. (2009) reported that a unified membrane fouling index (UMFI) could be applied to depict the trend of fouling behavior. They concluded that no doi: 10.2166/ws.2013.189 significant correlation between UMFI and turbidity (NTU) or total organic carbon (TOC) was found, but the properties of the membrane played an important role in UMFI. Other research (Huang et al. 2008) proposed a modified fouling index model for the LPM filtration process at constant flux. This model was based on a theory of cake layer formation to determine a reversible fouling index and intermediate pore blocking to govern the irreversible fouling index. Different types of fouling indices could be calculated using different data, and each model could describe membrane fouling behavior to various degrees. Nevertheless, the membrane fouling process was extremely complex and caused by various substances and combined effects. Recently, Nguyen et al. (20II) developed a novel fouling index (FI) which was not attributed to any special mechanism, but the definition of different fouling operational cycles 
was not clear enough. Therefore, it is important to establish a simple model to describe the membrane fouling behavior in different cycles clearly.

This paper focused on further development of the fouling index which had been proposed by Nguyen et al. (20II) to estimate fouling behavior in NOM ultrafiltration (UF) process. The FI was not attributed to a specific mechanism and different operational cycles of fouling were clearly defined and described. One advantage of this FI was that the ratio of reversible and irreversible fouling could be acquired by calculating different indices. It might be a good tool with simple calculation to describe and examine the membrane fouling behavior.

\section{MATERIALS AND METHODS}

\section{Organic foulants}

Three organic substances, bovine serum albumin (BSA), sodium alginate (SA) and humic acid (HA) were chosen to represent the typical NOM in drinking water. The HA stock solution was prepared by dissolving $1 \mathrm{~g}$ of $\mathrm{HA}$ (Sigma-Aldrich, USA) into $500 \mathrm{~mL} \mathrm{NaOH} \mathrm{(0.01} \mathrm{mol/L)} \mathrm{sol-}$ ution. The protein and polysaccharide stock solutions were BSA and SA (from brown algae) purchased from Genview (0BS10440, purity >99\%) and Sigma-Aldrich (A2158). The two solutions were dissolved in $500 \mathrm{~mL}$ deionized (DI) water with $1 \mathrm{~g}$ of BSA or SA respectively. All solutions were stirred for $24 \mathrm{~h}$, and then filtered through a $0.45 \mu \mathrm{m}$ fiber membrane to remove residual non-dissolved matter. The stock solutions were stored in sterilized glass bottles at $4{ }^{\circ} \mathrm{C}$. The properties of the feed water are summarized in Table 1.

\begin{tabular}{lllll} 
Table $\mathbf{1} \mid$ & The characteristics of the synthetic water \\
& $\mathbf{T O C}(\mathbf{m g} / \mathbf{L})$ & $\left.\mathbf{U V}_{\mathbf{2 5 4}} \mathbf{( c m}^{-\mathbf{1}}\right)$ & $\mathbf{S U V A}^{\mathbf{a}} \mathbf{( \mathbf { L } \cdot ( \mathbf { m ~ m g } ) ^ { - \mathbf { 1 } } )}$ & $\mathbf{p H}$ \\
\hline HA & $10 \pm 0.239$ & $1.016 \pm 0.01$ & 10.16 & $6.95 \pm 0.04$ \\
BSA & $10 \pm 0.27$ & $0.025 \pm 0.002$ & 0.25 & $7.13 \pm 0.03$ \\
SA & $10 \pm 0.4$ & $0.009 \pm 0.0001$ & 0.09 & $7.08 \pm 0.03$ \\
\hline
\end{tabular}

${ }^{a}$ The SUVA value represented the aromaticity of dissolved organic matter, which is calculated by $\mathrm{UV}_{254}$ and $\mathrm{DOC}\left(\mathrm{UV}_{254} / \mathrm{DOC} \times 100\right)$.

\section{The hollow-fiber polyvinyl chloride membrane module}

The hollow-fiber UF membrane module used in this study was made of polyvinyl chloride (PVC). It had a filtration area of $0.01 \mathrm{~m}^{2}$, with the inner and outer diameters of 0.85 and $1.45 \mathrm{~mm}$, respectively (Litree Co., Hainan, China). According to the manufacturer, the nominal pore size of the membrane was $0.01 \mu \mathrm{m}$ and molecular weight cutoff (MWCO) was $50 \mathrm{kDa}$. Each module contained 10 membrane fibers, with an effective length of $23.0 \pm 1 \mathrm{~cm}$. The contact angle of the PVC membrane was measured as $33.67^{\circ}$, indicating a hydrophilic property.

\section{Dead-end UF test}

A schematic diagram of the UF system used in this study is shown in Figure 1. All experiments were performed at a constant transmembrane pressure (TMP) of $30 \pm 0.5 \mathrm{kPa}$ with a stirred dead-end mode. To conduct the experiments under the same conditions, a virgin membrane module was used in every run. Prior to ultrafiltration, the virgin membrane was soaked in DI water for $24 \mathrm{~h}$. The pure water flux $\left(\mathrm{J}_{0}\right)$ set at $60 \pm 3 \mathrm{~L} /\left(\mathrm{m}^{2} \mathrm{~h}\right)$ was achieved at about $30 \mathrm{~min}$. Fouling behavior of each organic substance was evaluated at a feed concentration of $10 \mathrm{mg} / \mathrm{L}$ (dissolved organic carbon, DOC) under neutral $\mathrm{pH}$ (6.9-7.2). The fouling experiment was performed for $6.0 \mathrm{~h}$ with the flux recorded as $J^{\prime}$. At the end of the fouling experiment, hydraulic washing was performed for $5 \mathrm{~min}$ at an intensity of $0.2 \mathrm{~m}^{3} / \mathrm{m}^{2}$ by using air bubbles. Then the membrane was filtrated with DI water for $30 \mathrm{~min}$ under TMP of $80 \mathrm{kPa}$. After that, the pure water flux under $30 \mathrm{kPa}$ was denoted as the recovery of hydraulic washing $\left(J_{\mathrm{hbw}}\right)$. The membrane module was further soaked in $500 \mathrm{~mL} \mathrm{NaOH}(0.01 \mathrm{~mol} / \mathrm{L})$ for $24 \mathrm{~h}$ in order to remove the chemical reversible foulants. After thoroughly washing with DI water, the pure water flux was depicted as $J_{c c}$. Every experiment was repeated three times.

\section{Analytical methods}

DOC was measured with a TOC analyzer (TOC-VCPH, Shimadzu, Japan). UV absorbance at $254 \mathrm{~nm}$ $\left(\mathrm{UV}_{254}\right)$ was analyzed using a spectrometer (U-2910, 


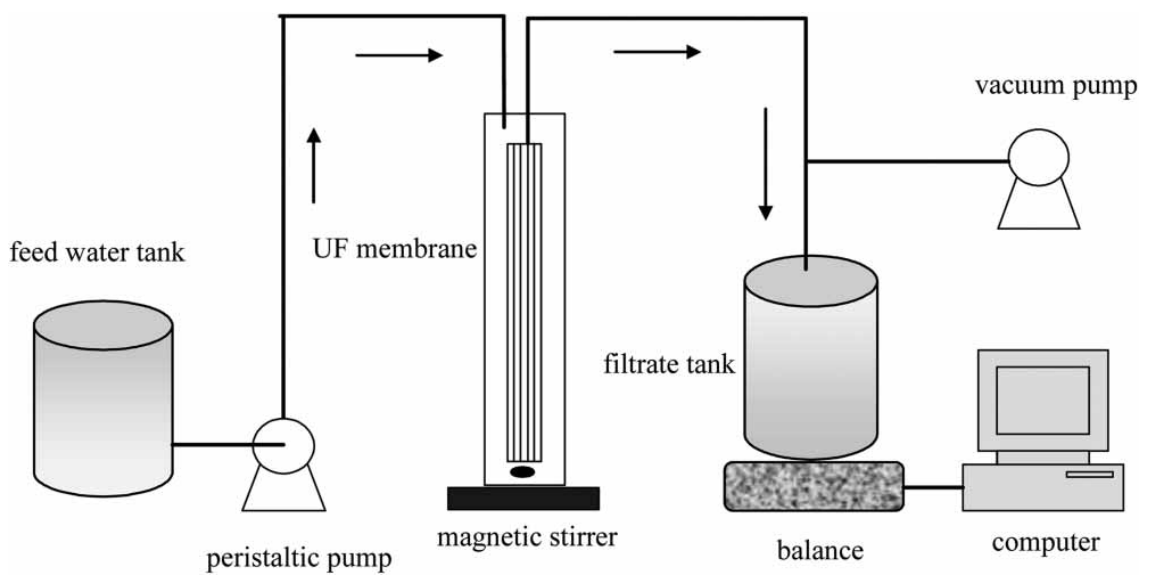

Figure 1 Schematic diagram of the experimental ultrafiltration unit.

Hitachi, Japan). All of the samples were filtered through a $0.45 \mu \mathrm{m}$ cellulose fabric membrane before these measurements were taken.

Solution zeta potential was determined by a Malvern Zetasizer 2000 (Malvern Instruments, UK). Surface zeta potential (streaming potential) was characterized by electrophoretic mobility and dynamic light scattering (DLS) using a DelsaNano C zeta potential analyzer (Beckman-Coulter, USA). Surface zeta potential is the potential at the electrokinetic slipping plane between the surface and solution when relative motion occurs between them. It has often been used in membranes to infer the charge of surface and pores or channels, and it is an important parameter of membranes which can influence fouling behavior. The principle of streaming potential can be found in previous research (Lanteri et al. 20II).

\section{Theoretical basics}

Membrane permeate flux can be described by the resistancein-series model:

$J=\frac{\Delta P}{\mu R}$

where $J$ is the permeate flux $\left(\mathrm{m}^{3} / \mathrm{m}^{2} \cdot \mathrm{s}\right), \Delta P$ is the transmembrane pressure $(\mathrm{Pa}), \mu$ is the dynamic viscosity of the solution (Pa.s), $R$ is the total resistance of the membrane $(1 / \mathrm{m})$. In general, the total resistance is the sum of the resistance of the virgin membrane $\left(R_{m}, 1 / \mathrm{m}\right)$ and the resistance due to fouling $\left(R_{f}, 1 / \mathrm{m}\right)$, as summarized in Equation (2):

$R_{t}=R_{m}+R_{f}$

The permeate volume can be written as follows:

$V=Q t / A$

where $V$ is the cumulative permeate volume $\left(\mathrm{m}^{3}\right), Q$ is the liquid velocity (m/s), $t$ is the filtration time (s) and $A$ is the membrane effective area $\left(\mathrm{m}^{2}\right)$.

According to Nguyen et al. (20II), if the resistances due to fouling increased linearly with the volume of permeate produced, then:

$R=k V$

where $k$ is a constant rate for the increase in resistance $\left(1 / \mathrm{m}^{4}\right)$, and $V$ is cumulative permeate volume $\left(\mathrm{m}^{3}\right)$. It indicates that membrane fouling resistance increased with the permeate volume. By inserting Equation (2) into (4), the following is yielded:

$R=R_{m}+R_{f}=R_{m}+k V$

Therefore, Equation (1) can be expressed as follows:

$J=\frac{\Delta P}{\mu R}=\frac{\Delta P}{\mu\left(R_{m}+k V\right)}$ 
For a virgin membrane, the permeate volume $V=0$, therefore:

$J_{0}=\frac{\Delta P}{\mu R_{m}}$

For a fouling membrane, assuming $V=V^{\prime}$, so:

$J^{\prime}=\frac{\Delta P}{\mu\left(R_{m}+k V^{\prime}\right)}$

If the TMP is constant, combining Equations (7) and (8):

$\mu R_{m} J_{0}=\mu\left(R_{m}+k V^{\prime}\right) J^{\prime}$

Hence:

$\frac{J_{0}}{J^{\prime}}=1+\frac{k}{R_{m}} V$

We defined $k / R_{m}$ as the membrane fouling index (FI, $1 / \mathrm{m}^{3}$ ), so Equation (10) was rewritten as:

$J_{0} / J^{\prime}=1+(\mathrm{FI}) V$

According to Equation (11), the value of FI can be calculated by the cumulative permeate volume and flux. During the membrane operational process, various values of FI can be calculated through the monitoring data. Therefore, FI can represent membrane performance and a high value means serious membrane fouling. For any fouling process without hydraulic washing, the total fouling index (TFI, $1 / \mathrm{m}^{3}$ ) can be defined as:

$J_{0} / J^{\prime}=1+(\mathrm{TFI}) V$

Compared to previous research (Huang et al. 2008), Equation (12) has the advantage that it was not necessary to distinguish the fouling mechanism.

For a fouling process with hydraulic washing and without chemical cleaning, the hydraulic irreversible fouling index (HIFI, $1 / \mathrm{m}^{3}$ ) can be expressed as follows:

$J_{0} / J_{\mathrm{hbw}}=1+(\mathrm{HIFI}) V$ where $J_{\mathrm{hbw}}$ is the pure water flux after hydraulic washing $\left(\mathrm{m}^{3} / \mathrm{m}^{2} \cdot \mathrm{s}\right)$.

After hydraulic washing and chemical cleaning, the chemical irreversible fouling index (CIFI, $\left.1 / \mathrm{m}^{3}\right)$ is acquired:

$J_{0} / J_{\mathrm{cc}}=1+(\mathrm{CIFI}) V$

where $J_{\mathrm{cc}}$ is the pure water flux after hydraulic washing and chemical cleaning $\left(\mathrm{m}^{3} / \mathrm{m}^{2} \cdot \mathrm{s}\right)$.

Membrane fouling can be divided into reversible and irreversible fouling. The former is removed by hydraulic washing, and the latter can be removed by chemical cleaning. Therefore, Equation (15) can be obtained:

$\mathrm{TFI}=\mathrm{RFI}+\mathrm{HIFI}=\mathrm{RFI}+\mathrm{CRFI}+\mathrm{CIFI}$

where RFI is the reversible fouling index $\left(1 / \mathrm{m}^{3}\right)$ and CRFI is the chemical reversible fouling index $\left(1 / \mathrm{m}^{3}\right)$, which is a part of CIFI $\left(1 / \mathrm{m}^{3}\right)$.

If the flux is constant, combining Equations (7) and (8):

$\frac{\Delta P^{\prime}}{\Delta P_{0}}=1+(F I) V$

Therefore, according to FI, the final pressure loss needed to filter water over time can be calculated. Furthermore, FI is not significantly correlated with feed water chemical characteristics, which indicates it is a suitable tool to depict membrane performance in a low pressure filtration process (Huang et al. 2009).

\section{$\overline{\text { RESULTS AND DISCUSSION }}$}

\section{Membrane performance}

Normalized flux values of experiments with different organic substances are shown in Figure 2. The flux decreased much more severely during filtration of BSA in comparison to HA and SA at the same DOC concentration during a short term filtration $(6 \mathrm{~h})$. BSA solution showed a total flux decline to a value of $0.29\left(J^{\prime} / J_{0}\right)$ in comparison to HA (0.40) and SA (0.37). However, the trend of flux decline 


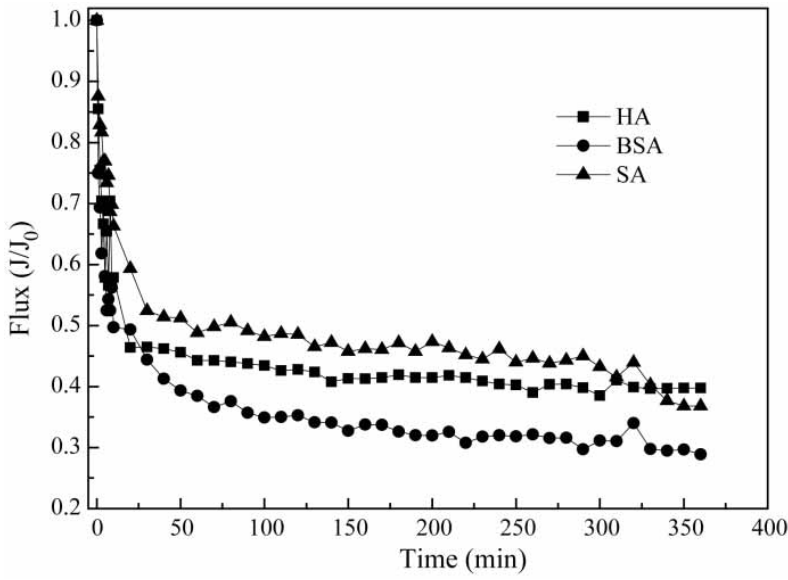

Figure 2 | Variation of fouling resistance with time.

was similar with a rapid decrease in the beginning (initial $30 \mathrm{~min}$ ) and then a constant permeability loss, so the whole process could be recognized as a fast response process (initial filtration) and a slow response process. This result revealed that different fouling mechanisms governed two filtration stages. Foulant-membrane interactions determined fouling behavior in the fast response process, while foulant-foulant interactions dictated the performance in the slow one (Huisman et al. 2000). Firstly, organics caused pore plugging or were absorbed on the membrane surface, which resulted in reduction of the effective permeate area (Wei \& Zydney 2000; Costa \& Pinho 2005). Then, a cake layer was formed and accumulated on the membrane surface, leading to further decrease in flux, which was also reported by other research (Ye et al. 2005; Bolton et al. 2006).

\section{Mass balances}

The mass balance was calculated for all experiments and is presented in Figure 3. As the molecular weight (MW) of the HA (about $4 \mathrm{kDa}$ ) was 10 times lower than the MWCO of the membrane, size exclusion cannot take place and the rejection of NOM should therefore be attributed to the adsorption of molecules onto the membrane. As the MWs of the BSA $(18-25 \mathrm{kDa})$ and SA $(40 \mathrm{kDa})$ were in the range of the smaller pores of the membrane $(50 \mathrm{kDa})$, initial pore blocking and cake formation in the later phase of the filtration were proposed. The calculation of the mass

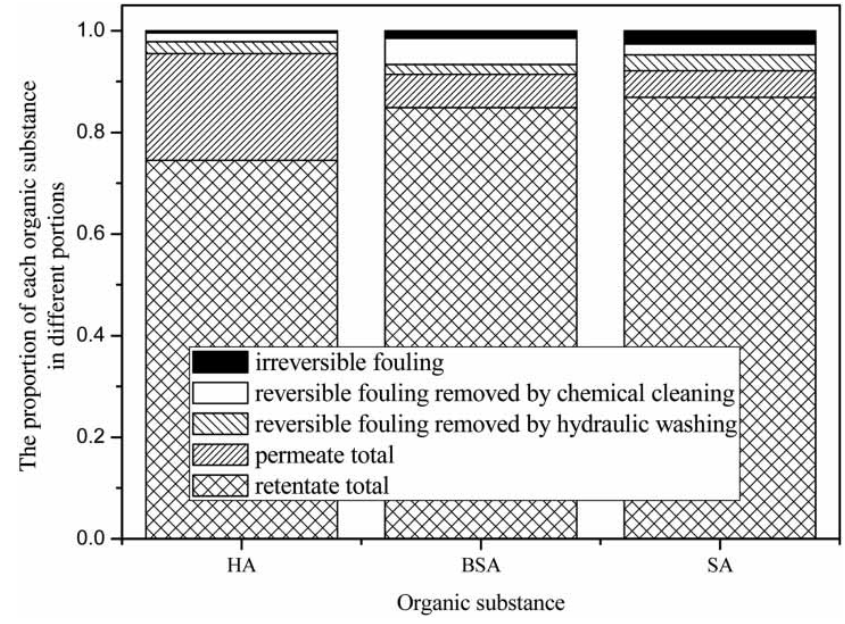

Figure 3 | Mass balance of each organic substance during the experiments.

balance showed 4.5\% (HA), 8.6\% (BSA) and 7.9\% (SA) adsorption, respectively. However, the chemically irreversible fouling contributed a little. A relatively small amount of HA $(0.03 \%)$ caused chemically irreversible fouling, while SA showed an increased irreversible adsorption $(2.6 \%)$ on the membrane. In addition, a large part of irreversible fouling caused by BSA could be removed by chemical cleaning. This finding suggested that only a small fraction of DOC was responsible for chemically irreversible fouling. Likewise, others have suggested that only $10-15 \%$ of DOC could cause membrane fouling (Koh et al. 2005).

\section{Correlations of membrane fouling and hydrophobicity and zeta potential}

According to our previous research (Xiao et al. 2012), the PVC membrane was hydrophilic. As Table 1 shows, the value of specific ultraviolet absorption (SUVA) for HA is $10.16 \mathrm{~L} \cdot(\mathrm{m} \cdot \mathrm{mg})^{-1}$, which indicates a strong hydrophobicity, while values of SUVA for BSA and SA are $0.25 \mathrm{~L} \cdot(\mathrm{m} \cdot \mathrm{mg})^{-1}$ and $0.09 \mathrm{~L} \cdot(\mathrm{m} \cdot \mathrm{mg})^{-1}$, showing them to be more hydrophilic. The hydrophobic interaction may occur between the membrane and organic foulants. The results of mass balance revealed about $21 \%$ of HA permeated through the membrane and only 4.5\% adsorbed on the membrane (Figure 3). Moreover, BSA and SA showed relatively small amounts of permeate (6.5 and 5.2\%) and increasing 
amounts being adsorbed (8.6 and 7.9\%). It demonstrated that the adsorption of hydrophilic organics (BSA and SA) was greater than that of the hydrophobic organic (HA). Similar results are found in other research (Jermann, et al. 2007). The hydrophobic interaction played a role in membrane fouling.

After all filtration experiments, the membrane zeta potential shifted to more negative values (Figure 4), indicating that negatively charged foulants were absorbed on the membrane (Elimelech \& Childress 1996; Shim et al. 2002; Contreras et al. 2009). It is worth noting that the changes of membrane surface zeta potential were consistent with those of the solutions. Adsorption of the highly negatively charged foulants led to an increase in the magnitude of the negative zeta potential of the membrane surface, while less negatively charged solutions just caused a small increase in the membrane potential. Consequently, it can be concluded that fouling behavior of organic substances in ultrafiltration might be a result of combined effects related to both hydrophobic interaction and electrostatic interaction (Madaeni et al. 2006).

\section{Fouling index in different stages}

The values of FI were calculated according to Equation (12). TFI value variations were quite significant between organic substances. The order of TFI (average) was as following: BSA $\left(0.0371 \pm 0.00461 / \mathrm{m}^{3}\right)>\mathrm{HA}\left(0.0162 \pm 0.00231 / \mathrm{m}^{3}\right)>$ SA $\left(0.0134 \pm 0.00191 / \mathrm{m}^{3}\right)$, consistent with the order of flux (Figure 5). Overall, $\mathrm{FI}_{\mathrm{S}}$ was in the range from $0.0011 / \mathrm{m}^{3}$ to $0.0071 / \mathrm{m}^{3}$, while fast stage $\left(\mathrm{FI}_{\mathrm{Ft}}\right)$ was between
$0.031 / \mathrm{m}^{3}$ and $0.081 / \mathrm{m}^{3}$. In the fast fouling stage, NOM caused pore blocking and was absorbed or deposited on the membrane surface, hence the flux decreased rapidly. Subsequently flux came to a constant loss with much lower FI values.

At the end of filtration, the flux $\left(J^{\prime} / J_{0}\right)$ of HA, BSA and SA was reduced to $0.3812,0.2538$ and 0.3776 , respectively. Hydraulic washing and chemical cleaning were then carried out to investigate the recovery. After hydraulic washing, the flux $\left(\mathrm{Jbw}_{\mathrm{hb}} / J_{0}\right)$ was increased to $0.7382(\mathrm{HA}), 0.2878$ (BSA) and 0.7436 (SA), respectively (Figure 6). In the case of HA and SA, the high recovery after hydraulic washing indicated that a type of cake layer was the major type of fouling which was reversible, while for BSA pore blocking and adsorption which was irreversible seemed to be dominant. However, most of the irreversible fouling caused by BSA could be removed by chemical cleaning. Myat et al. (2009) have reported that the fouling mechanism is time dependent. Hence, both of the two fouling stages (fast and slow) are important in membrane performance.

The recovery after chemical cleaning in the case of HA was increased beyond $99 \%\left(J_{\mathrm{cc}} / J_{0}\right)$. It should be noted that the membrane contact angle (Table 2) was changed. Most of the foulants were removed after being soaked in $\mathrm{NaOH}$ solution, which contributed to improvement of surface hydrophilicity. Meanwhile, hydroxyl ions may also absorb onto the membrane surface and also improve the hydrophilicity (Li \& Elimelech 2004). The contact angle (of the fouled membrane after being cleaned) reduced from $44.29^{\circ}$ to $33.99^{\circ}$ (HA), $49.46^{\circ}$ to $42.32^{\circ}$ (BSA) and $45.42^{\circ}$ to 42.22 (SA). After chemical cleaning, the contact angle of the HA (a)

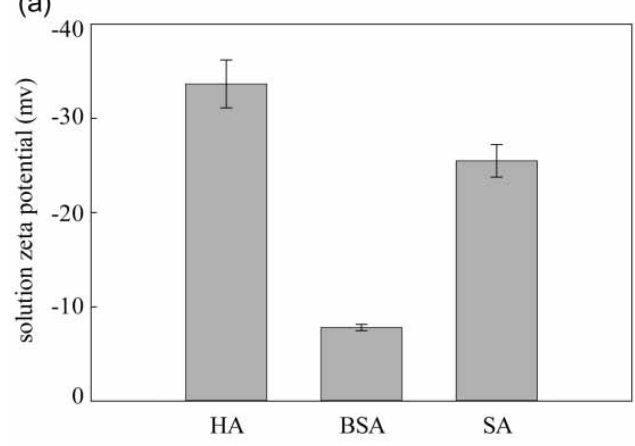

(b)

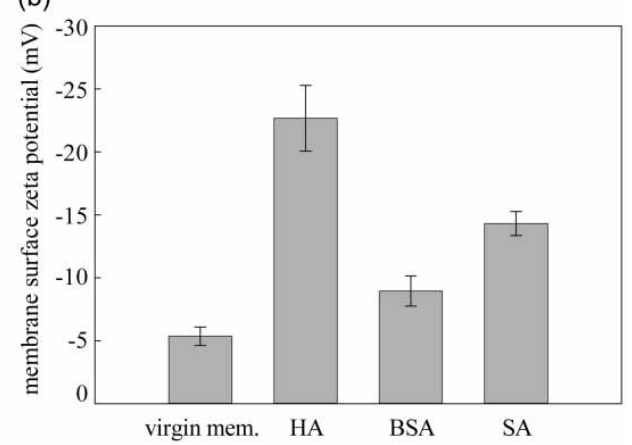

Figure 4 | Zeta potential of feed water (a) and membrane surface after fouling (b). 


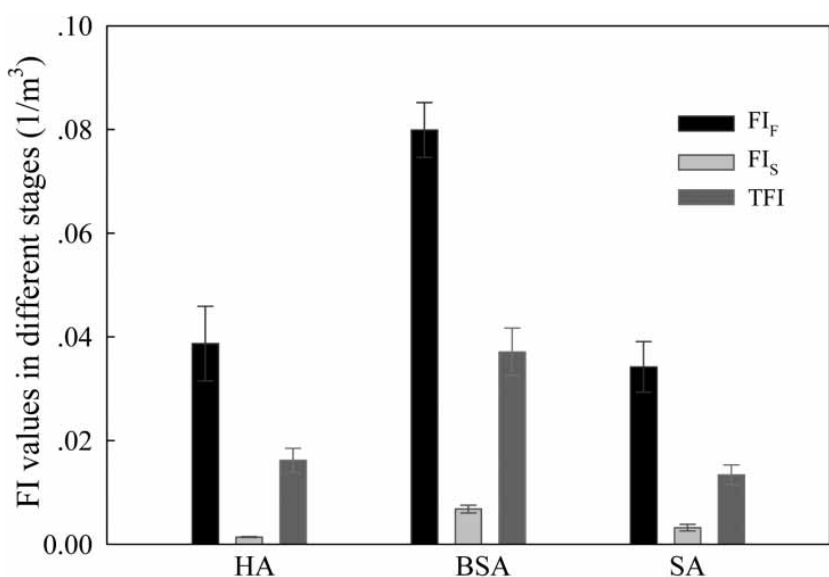

Figure 5 | Fouling index in different stages.

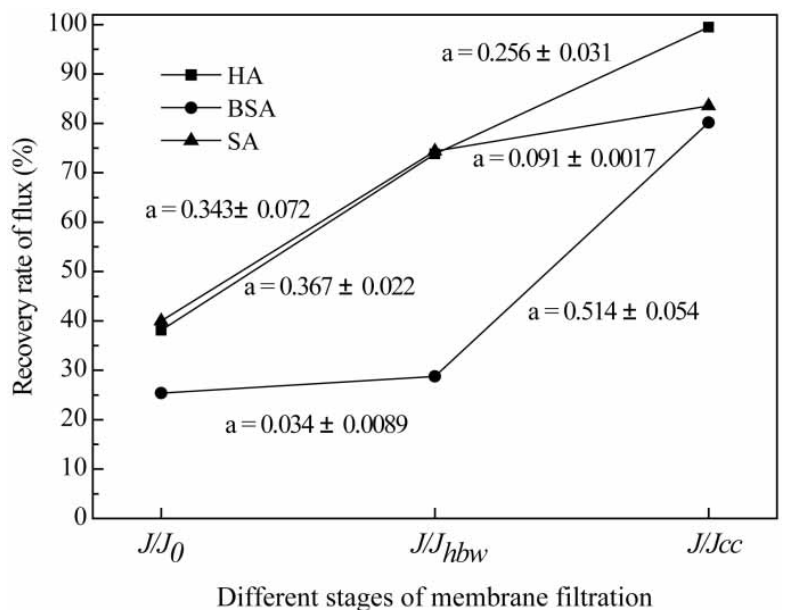

Figure 6 | Variation of flux in different operational cycles.

Table 2 | The contact angles of the membrane

\begin{tabular}{|c|c|c|c|c|c|}
\hline & \multicolumn{4}{|c|}{ Contact angle ( ) } \\
\hline & & $\mathbf{R 1}^{\mathbf{a}}$ & R2 & R3 & Average \\
\hline \multicolumn{2}{|c|}{ New membrane } & 32.89 & 35.01 & 33.12 & 33.67 \\
\hline \multirow[t]{2}{*}{ HA } & Fouled membrane & 40.5 & 45.6 & 46.78 & 44.29 \\
\hline & $\begin{array}{l}\text { Membrane after chemical } \\
\text { cleaning }\end{array}$ & 34.5 & 33.78 & 33.69 & 33.99 \\
\hline \multirow[t]{2}{*}{ BSA } & Fouled membrane & 50.65 & 48.22 & 47.1 & 49.46 \\
\hline & $\begin{array}{l}\text { Membrane after chemical } \\
\text { cleaning }\end{array}$ & 41.64 & 42.88 & 42.43 & 42.32 \\
\hline \multirow[t]{2}{*}{ SA } & Fouled membrane & 46.33 & 43.19 & 46.75 & 45.42 \\
\hline & $\begin{array}{l}\text { Membrane after chemical } \\
\text { cleaning }\end{array}$ & 42.72 & 43.61 & 40.32 & 42.22 \\
\hline
\end{tabular}

${ }^{\mathrm{a}} \mathrm{R}$ denotes run.

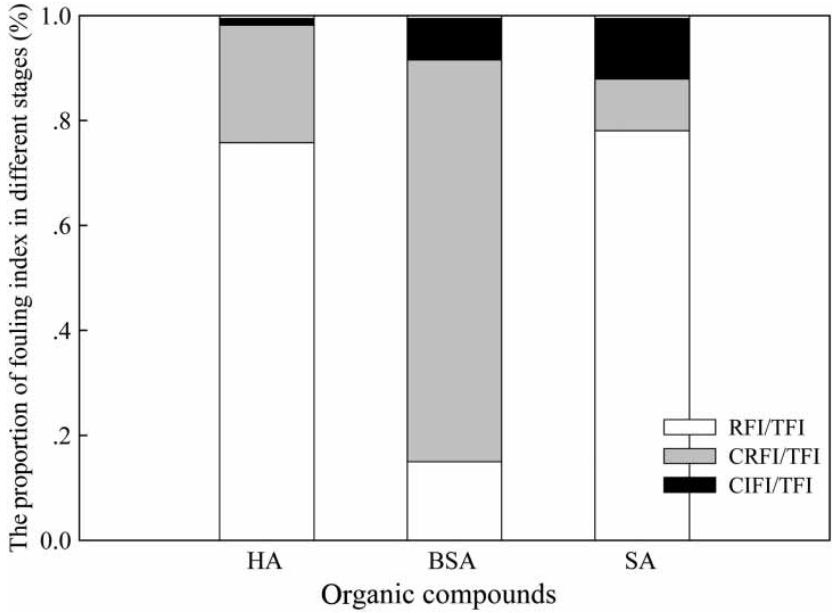

Figure 7 | The proportion of membrane fouling index in different operational cycles.

$\left(33.99^{\circ}\right)$ fouled membrane was close to that of the virgin membrane $\left(33.67^{\circ}\right)$. Additionally, a low recovery for SA associated with a higher contact angle after chemical cleaning showed the formation of irreversible chemical fouling. This result is consistent with our previous research (Xiao et al. 20I2).

Hydraulic washing/chemical cleaning could be effective, resulting in a higher value of RFI/CRFI, or ineffective, resulting in a lower value of RFI/CRFI. Figure 7 presents the data for RFI, CIFI and CRFI. The values for different operational cycles varied significantly, due to the variable effectiveness of hydraulic washing and chemical cleaning even though the chemical cleaning procedure was kept constant. The value of RFI for BSA was the lowest $\left(0.005551 / \mathrm{m}^{3}\right)$, showing the most serious irreversible fouling. But a relatively high CRFI $\left(0.02841 / \mathrm{m}^{3}\right)$ value showed that a large part was removed by chemical cleaning. In addition, the irreversible fouling caused by SA was difficult to remove with alkaline cleaning, resulting in a low value of CRFI $\left(0.001321 / \mathrm{m}^{3}\right)$. The variations of FI values were consistent with the results of mass balances and flux recovery, which confirmed that FI developed based on a resistance-in-series model could be a useful tool to describe membrane performance in different operational cycles.

\section{CONCLUSIONS}

1. The fouling caused by NOM can be considered as two steps, a fast fouling stage followed by a slow one. When 
the flux declined more rapidly it suggested a faster fouling and a higher FI. Both the fast response and slow response had important effects on the filtration process with different fouling mechanisms. The fouling behavior of organic foulants in ultrafiltration has been attributed to a combined action of hydrophobic interaction and electrostatic interaction.

2. The order of TFI (average) was as follows: BSA $>\mathrm{HA}>$ SA, consistent with the order of flux, and the sequences of irreversible fouling after chemical cleaning was SA > BSA $>$ HA. Irreversible fouling caused by HA and BSA could be easily removed by alkaline soaking, while chemical cleaning had a rather limited effect on irreversible fouling caused by SA.

3. The variations of FI values were consistent with the results of mass balances and flux variation, which revealed that this method was validated and reliable. Different fouling indices were determined to describe different operational cycles. FI with a simple expression was shown to be a useful tool to describe membrane performance.

\section{ACKNOWLEDGEMENTS}

This research was supported by grants from the National Natural Science Foundation of China (Nos 51138008, 51008293 and 51025830) and from the Major Science and Technology Program for Water Pollution Control and Treatment (Nos 2011ZX07410-002 and 2012ZX07408-00105).

\section{REFERENCES}

Bolton, G., LaCasse, D. \& Kuriyel, R. 2006 Combined models of membrane fouling: development and application to microfiltration and ultrafiltration of biological fluids. $J$. Membr. Sci. 277 (1-2), 75-84.

Contreras, A. E., Kim, A. \& Li, Q. L. 2009 Combined fouling of nanofiltration membranes: mechanisms and effect of organic matter. J. Membr. Sci. 2009 (1-2), 87-95.

Costa, A. P. \& Pinho, M. N. 2005 Effect of membrane pore size and solution chemistry on the ultrafiltration of humic substances solutions. J. Membr. Sci. 225 (1-2), 49-56.
Elimelech, M. \& Childress, A. E. 1996 Zeta Potential of Reverse Osmosis Membranes: Implications for Membrane Performance. Report Bureau of Reclamation, Water Treatment Technology Program No. 10, Denver, USA.

Fan, L. H., Harris, J. \& Roddick, F. A. 20or Influence of the characteristics of natural organic matter on the fouling of microfiltration membranes. Water Res. 35 (18), 4455-4463.

Howe, K. J. \& Clark, M. M. 2002 Fouling of microfiltration and ultrafiltration membranes by natural waters. Environ. Sci. Technol. 36 (16), 3571-3576.

Huang, H., Thayer, Y. \& Jacangelo, J. 2008 Unified membrane fouling index for low pressure membrane filtration of natural waters: principles and methodology. Environ. Sci. Technol. 42 (3), 714-720.

Huang, H., Thayer, Y. \& Jacangelo, J. 2009 Novel approach for the analysis of bench-scale, low pressure membrane fouling in water treatment. J. Membr. Sci. 334 (1-2), 1-8.

Huisman, I. H., Pradanos, P. \& Hernandez, A. 2000 The effect of protein-protein and protein- membrane interactions on membrane fouling in ultrafiltration. J. Membr. Sci. 179 (1-2), 79-90.

Jermann, D., Pronk, W., Meylan, S. \& Boller, M. 2007 Interplay of different NOM fouling mechanisms during ultrafiltration for drinking water production. Water Res. 41 (8), 1713-1722.

Koh, M., Clark, M. M. \& Howe, K. J. 2005 Filtration of lake natural organic matter: adsorption capacity of a polypropylene microfilter. J. Membr. Sci. 256 (1-2), 169-175.

Lanteri, Y., Fievet, P., Magnenet, C., Déon, S. \& Szymczyk, A. 20 II Electrokinetic characterisation of particle deposits from streaming potential coupled with permeate flux measurements during dead-end filtration. J. Membr. Sci. 378 (1-2), 224-232.

Li, Q. L. \& Elimelech, M. 2004 Organic fouling and chemical cleaning of nanofiltration membranes: measurements and mechanisms. Environ. Sci. Technol. 38 (17), 4683-4693.

Madaeni, S. S., Sedeh, S. N. \& Denobili, M. 2006 Ultrafiltration of humic substances in the presence of protein and metal ions. Transp. Porous Med. 65 (3), 469-484.

Myat, D. T., Mergen, M., Zhao, O., Stewart, M. B., Orbell, J. D., Merle, T., Croué, J. P. \& Gray, S. 2009 Effect of IX dosing on polypropylene and PVDF membrane fouling control. Water Res. 47 (11), 3827-3834.

Nguyen, A. H., Tobiason, J. E. \& Howe, K. J. 20II Fouling indices for low pressure hollow fiber membrane performance assessment. Water Res. 45 (8), 2627-2637.

Peter-Varbanet, V., Margot, J., Traber, J. \& Pronk, W. $201 \mathrm{I}$ Mechanism of membrane fouling during ultra-low pressure ultrafiltration. J. Membr. Sci. 377 (1-2), 42-53.

Shim, Y., Joolee, H., Lee, S. Y., Moon, S. H. \& Cho, J. 2002 Effects of natural organic matter and ionic species on membrane surface charge. Environ. Sci. Technol. 36 (17), 3864-3871.

Wei, Y. \& Zydney, A. L. 2000 Humic acid fouling during ultrafiltration. Environ. Sci. Technol. 34 (23), 5043-5050.

Xiao, P., Xiao, F., Wang, D. S., Qin, T. \& He, S. P. 2012 Investigation of organic foulants behavior on hollow-fiber UF 
membranes in a drinking water treatment plant. Sep. Purif. Technol. 95, 109-117.

Yamamura, H., Kimura, K. \& Watanabe, Y. 2007 Mechanism involved in the evolution of physically irreversible fouling in microfiltration and ultrafiltration membranes used for drinking water treatment. Environ. Sci. Technol. 41 (19), 6789-6794.

Ye, Y., Le Clech, P., Chen, V., Fane, A. G. \& Jefferson, B. 2005 Fouling mechanisms of alginate solutions as model extracellular polymeric substances. Desalination 175 (1), 7-20.

First received 14 May 2013; accepted in revised form 30 July 2013. Available online 13 September 2013 